\title{
Prognostic factors in patients with endocrine tumours of the duodenopancreatic area
}

\author{
I Madeira, B Terris, M Voss, A Denys, A Sauvanet, J-F Flejou, V Vilgrain, J Belghiti, \\ P Bernades, P Ruszniewski
}

\begin{abstract}
Background-The development of endocrine tumours of the duodenopancreatic area (ETDP) is thought to be slow, but their natural history is not well known. The aim of this study was to determine the factors that influence survival of patients with ETDP.

Patients/Methods-Eighty two patients with ETDP (44 non-functioning tumours, 23 gastrinomas, seven calcitoninsecreting tumours, four glucagonomas, three insulinomas, one somatostatinoma) followed from October 1991 to June 1997 were included in the study. The following factors were investigated: primary tumour size, hormonal clinical syndrome, liver metastases, lymph node metastases, extranodular/extrahepatic metastases, progression of liver metastases, local invasion, complete resection of the primary tumour, and degree of tumoral differentiation. The prognostic significance of these factors was investigated by uni- and multi-variate analysis.
\end{abstract}

Results-Twenty eight patients (34\%) died within a median of 17 months (range 1-110) from diagnosis. Liver metastases ( $p$ $=0.001)$, lymph node metastases ( $p=$ 0.001 ), progression of liver metastases $(p<0.00001)$, lack of complete resection of the primary tumour $(p=0.001)$, extranodular/extrahepatic metastases $(\mathbf{p}=$ $0.001)$, local invasion $(p=0.001)$, primary tumour size $\geqslant 3 \mathrm{~cm}(p=0.001)$, nonfunctioning tumours $(p=0.02)$, and poor tumoral differentiation $(p=0.006)$ were associated with an unfavourable outcome by univariate analysis. Multivariate analysis identified only liver metastases (risk ratio $(R R)=8.3 ; p<0.0001)$, poor tumoral cell differentiation $(R R=8.1 ; p=0.0001)$, and lack of complete resection of the primary tumour $(R R=4.8 ; p=0.0007)$ as independent risk factors. Five year survival rates were 40 and $100 \%$ in patients with and without liver metastases, 85 and $42 \%$ in patients with and without complete resection of primary tumour, and 17 and $71 \%$ in patients with poor and good tumour cell differentiation respectively.

Conclusion-Liver metastases are a major prognostic factor in patients with ETDP. Progression of liver metastases is also an important factor which must be taken into account when deciding on the therapeutic approach. The only other independent prognostic factors are tumoral cell differ- entiation and complete resection of the primary tumour. (Gut 1998;43:422-427)

Keywords: prognostic factors; survival; endocrine tumours; gastrinoma; cell differentiation; liver metastases

Endocrine tumours of the duodenopancreatic area (ETDP) are rare lesions with a supposedly slow evolution ${ }^{1}$ which can be detected by symptomatic hormone overproduction (functioning tumours); patients with nonfunctioning tumours tend to present with liver metastases at diagnosis. ${ }^{2}$ In all cases, the main challenge is the control of the tumoral process.

The prognostic factors of ETDP have not yet been clearly defined. The rarity of these tumours and their usually slow progression have made it difficult to define their natural history. In addition, many studies have included both ETDP and carcinoid tumours whereas these two entities should be considered separately. ${ }^{3}$ Moreover, traditional histo-

Table 1 Clinical characteristics in 82 patients with endocrine tumours of the duodenopancreatic area

\begin{tabular}{|c|c|}
\hline & No $(\%)$ \\
\hline \multicolumn{2}{|l|}{ Diagnosis } \\
\hline Non-functioning tumour & $44(54)$ \\
\hline Gastrinoma & $23(28)$ \\
\hline Calcitonin-secreting tumour & $7(8)$ \\
\hline Glucagonoma & $4(5)$ \\
\hline Insulinoma & $3(3.5)$ \\
\hline Somatostatinoma & 1 \\
\hline \multicolumn{2}{|l|}{ Size of the primary tumour } \\
\hline$<3 \mathrm{~cm}$ & $34(41.5)$ \\
\hline$\geqslant 3 \mathrm{~cm}$ & $48(58.5)$ \\
\hline \multicolumn{2}{|l|}{ Primary tumour site } \\
\hline Pancreas & $62(75.5)$ \\
\hline Duodenum & $13(16)$ \\
\hline Peri-pancreatic lymph nodes & $7(8.5)$ \\
\hline 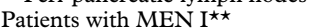 & $7(8.5)$ \\
\hline \multicolumn{2}{|l|}{ Patients with metastases } \\
\hline Liver & $49(60)$ \\
\hline Lymph nodes & $52(63.5)$ \\
\hline Other $\star \star \star \star$ & $15(18.5)$ \\
\hline \multicolumn{2}{|l|}{ Progression of liver metastases } \\
\hline Yes & $27(55)$ \\
\hline No & $4(8)$ \\
\hline Non evaluated & $18(37)$ \\
\hline \multicolumn{2}{|l|}{ Locoregional involvement } \\
\hline Yes & $26(32)$ \\
\hline No & $56(68)$ \\
\hline \multicolumn{2}{|l|}{ Tumour cell differentiation } \\
\hline Good & $64(78)$ \\
\hline Poor & $9(11)$ \\
\hline Non evaluated & $9(11)$ \\
\hline \multicolumn{2}{|c|}{ Complete resection of the primary tumour } \\
\hline Yes & $42(51)$ \\
\hline No & $40(49)$ \\
\hline
\end{tabular}

* Multiple tumours were observed in the duodenum of two patients with gastrinomas and in the pancreas of one patient with an insulinoma.

$\star \star$ Multiple endocrine neoplasia type I.

$\star \star \star$ Bones $n=8$, peritoneum $n=5$, lungs $n=4$, brain $n=2$, adrenal glands $n=2$ and skin $n=1$. 
logical and morphological assessments of the primary tumour (nuclear pleomorphism, prominent nucleoli, and infiltration of peritumoral acinar tissue) are not effective for predicting malignant behaviour. ${ }^{4}$ Only the presence of distant metastases, mainly hepatic or nodal, is a definitive criterion of malignancy.

Some recent studies have tried to assess new criteria, especially the determination of cell proliferation, ${ }^{5-9}$ in the discrimination of benign and malignant ETDP. However, none of these markers is routinely used in the management of patients with ETDP.

The present study evaluated the prognostic significance of several routinely used parameters in a large single centre series of patients with ETDP.

\section{Patients and Methods}

PATIENTS

Eighty two consecutive patients with ETDP seen in the Gastroenterology Department of Beaujon University Hospital were included in a retrospective study between October 1991 and June 1997.

Table 1 summarises the relevant clinical characteristics of the patients. There were 45 men and 37 women. Median age was 49.5 years (range 22-79). Median duration of follow up was 32 months (range 1-204) from diagnosis and 50 months (range 2-514) from the first clinical signs. Multiple tumours were observed in the duodenum in two patients with gastrinomas and in the pancreas in one patient with an insulinoma. Extranodular/extrahepatic metastases $(n=15)$ were found in the bones $(n=8)$, the peritoneum $(n=5)$, the lungs $(n=4)$, the brain $(n=2)$, the adrenal glands $(n=2)$, and the skin $(n=1)$.

The diagnosis of gastrinoma $(n=23)$ in patients with Zollinger-Ellison syndrome was based on specific biological criteria provided by a positive secretin infusion test - that is, basal acid output $\geqslant 31 \mathrm{mmol} \mathrm{H}^{+} / \mathrm{h}$ and/or secretin acid output $\geqslant 18 \mathrm{mmol} \mathrm{H} / \mathrm{h}$ and/or basal serum gastrin $\geqslant 325 \mathrm{pg} / \mathrm{ml}$ and/or serum gastrin after secretin infusion $\geqslant 270 \mathrm{pg} / \mathrm{ml}$. These criteria were derived from the study of 45 anatomically confirmed gastrinomas compared with duodenal ulcer patients. ${ }^{10}$ Histological confirmation of the gastrinoma was obtained in $17 / 23$ cases $(74 \%)$.

For all other patients with ETDP ( $\mathrm{n}=59$ ), the diagnosis was histologically confirmed by conventional and immunohistochemical techniques (neuron specific enolase, chromogranin $\mathrm{A}$, and staining with specific peptides according to tumoral secretion). For patients who had not received surgery $(n=19)$, diagnosis was based on analysis of biopsy samples of the primary tumour $(n=6)$, of liver metastases $(n=$ $11)$, or of lymph node metastases $(n=2)$.

Serum hormone levels (gastrin, vasoactive intestinal polypeptide, insulin, glucagon, calcitonin, somatostatin) were determined in all patients. The tumour was designated as non-functioning when no specific clinical signs were induced by hormonal overproduction. Among the 44 patients with non-functioning tumours, increases in plasma levels of both somatostatin and calcitonin were observed in four, and increases in plasma levels of several peptides (vasoactive intestinal polypeptide,

Table 2 Univariate analysis of prognostic factors in 82 patients with endocrine tumours of duodenopancreas

\begin{tabular}{|c|c|c|c|c|c|}
\hline \multirow[b]{2}{*}{ Variable } & \multicolumn{2}{|c|}{ Comparison of death rates } & \multicolumn{3}{|c|}{ Comparison of survival rates } \\
\hline & $\%$ of deaths & $p$ Value & $\begin{array}{l}\text { Risk ratio for } \\
\text { mortality } \\
(95 \% \text { CI })^{\star}\end{array}$ & $\begin{array}{l}5 \text { year } \\
\text { survival } \\
\text { rates (\%) }\end{array}$ & $p$ Value ${ }^{\star *}$ \\
\hline \multicolumn{6}{|l|}{ Sex } \\
\hline Male & 37.7 & \multirow[t]{2}{*}{$0.444 \dagger$} & \multirow[t]{2}{*}{$1.3(0.2$ to 4.1$)$} & 61.1 & \multirow[t]{2}{*}{0.446} \\
\hline Female & 29.7 & & & 65.3 & \\
\hline \multicolumn{6}{|c|}{ Liver metastases (LM) } \\
\hline Yes & 57.2 & \multirow[t]{2}{*}{$0.001 \dagger$} & \multirow[t]{2}{*}{$7.4(3.5$ to 15.7$) \ddagger$} & 40.2 & \multirow[t]{2}{*}{0.0001} \\
\hline No & 0.0 & & & 100 & \\
\hline \multicolumn{6}{|c|}{$\mathrm{LM}$ progression } \\
\hline Yes & 66.7 & \multirow[t]{2}{*}{$<0.0001+\dagger$} & \multirow[t]{2}{*}{ 拉 } & 34.4 & \multirow[t]{2}{*}{0.0001} \\
\hline No & 0.0 & & & 100.0 & \\
\hline \multicolumn{6}{|c|}{ Other metastases } \\
\hline Yes & 73.3 & \multirow[t]{2}{*}{$0.001 \dagger$} & \multirow[t]{2}{*}{$4.4(2.0$ to 9.5$)$} & 30.0 & \multirow[t]{2}{*}{0.0001} \\
\hline No & 25.3 & & & 70.5 & \\
\hline \multicolumn{6}{|c|}{ Locoregional involvement } \\
\hline Yes & 76.9 & \multirow[t]{2}{*}{$0.001 \dagger$} & \multirow[t]{2}{*}{$6.5(2.9$ to 14.9$)$} & 24.2 & \multirow[t]{2}{*}{0.0001} \\
\hline No & 14.3 & & & 86.5 & \\
\hline \multicolumn{6}{|c|}{ Cell differentiation of the tumour } \\
\hline Good & 28.2 & \multirow[t]{2}{*}{$0.006+t$} & \multirow[t]{2}{*}{11.7 (4.4 to 31.5$)$} & 70.6 & \multirow[t]{2}{*}{0.0001} \\
\hline Poor & 77.9 & & & 16.7 & \\
\hline \multicolumn{6}{|c|}{ Complete resection of the primary tumour } \\
\hline Yes & 14.3 & \multirow[t]{2}{*}{$0.001 \dagger$} & \multirow[t]{2}{*}{$4.8(2.0$ to 12.0$)$} & 85.3 & 0.0002 \\
\hline No & 55.0 & & & 42.0 & \\
\hline Lymph nod & & & & & \\
\hline Yes & 48.0 & $0.001 \dagger$ & $7.4(2.2$ to 25.2$)$ & 46.6 & 0.0002 \\
\hline No & 10.0 & & & 92.5 & \\
\hline Size of the & & & & & \\
\hline$<3 \mathrm{~cm}$ & 11.8 & $0.001 \dagger$ & $4.9(1.7$ to 14.3$)$ & 88.2 & 0.0011 \\
\hline$\geqslant 3 \mathrm{~cm}$ & 50.0 & & & 46.6 & \\
\hline Functionin & & & & & \\
\hline Yes & 22.5 & $0.02 \dagger$ & $2.7(1.2$ to 6.1$)$ & 73.6 & 0.009 \\
\hline No & 45.2 & & & 53.2 & \\
\hline
\end{tabular}

†The $\mathrm{p}$ value was calculated by $\chi^{2}$ test. ††The $\mathrm{p}$ value was calculated by Fisher's exact test. $¥$ Risk ratio calculated after the variable was forced in the Cox model. \#tRisk ratio not determined because of the lack of deaths in the group without progressive LM. ${ }^{\star} \mathrm{CI}$ denotes confidence interval. ${ }^{\star}$ The $\mathrm{p}$ value was calculated by the log rank test. 
Table 3 Frequency of liver metastases in 82 patients with endocrine tumours of the duodenopancreatic area, according to selected variables

\begin{tabular}{lrll}
\hline Variable & $n$ & Liver metastases No (\%) & p Value \\
\hline Primary tumour size & 34 & $12(35.5)$ & 0.001 \\
$\quad<3 \mathrm{~cm}$ & 48 & $37(77)$ & \\
$\quad \begin{array}{l}\text { * cm } \\
\text { Functioning tumour }\end{array}$ & 40 & $19(47.5)$ & 0.043 \\
$\quad$ Yes & 42 & $30(71.5)$ & \\
$\quad$ No & 52 & $38(73)$ & 0.001 \\
Lymph node metastases & 30 & $11(36.5)$ & \\
$\quad$ Yes & 15 & $14(93.5)$ & 0.003 \\
$\quad$ No & 67 & $35(52)$ & \\
Other metastases & 26 & $24(92.5)$ & 0.001 \\
$\quad$ Yes & 56 & $25(44.5)$ & \\
$\quad$ No & 64 & $38(59.5)$ & 0.086 \\
Local involvement of tumour & 9 & $8(89)$ & \\
$\quad$ Yes & & & \\
$\quad$ No & & \\
$\quad$ Goll differentiation of tumour & & & \\
Poor & & & \\
\hline
\end{tabular}

^The $\mathrm{p}$ value was calculated by $\chi^{2}$ test.

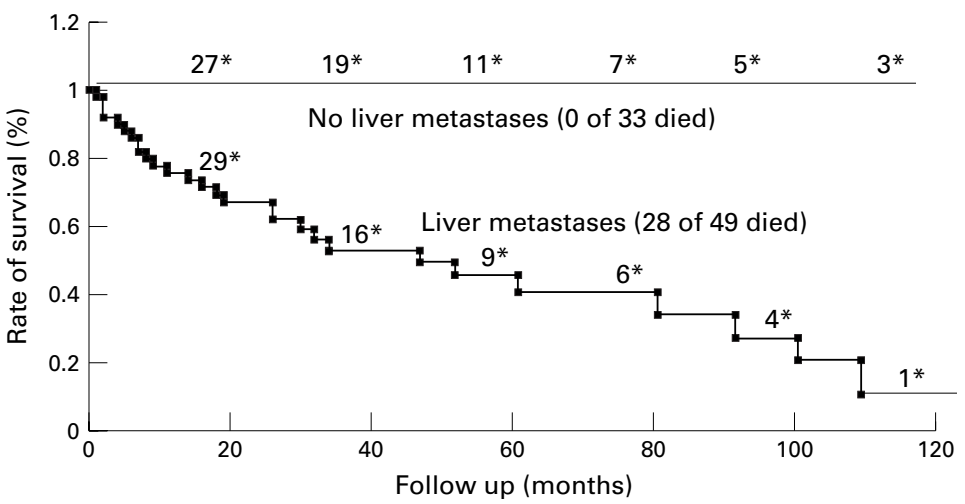

Figure 1 Overall survival after diagnosis among 82 patients with endocrine tumours of the duodenopancreatic area, according to the presence of liver metastases (log rank test; $p=$ 0.0001). The asterisks indicate the number of patients at risk.

gastrin, glucagon, somatostatin, calcitonin) were observed in three.

Seven patients presented with multiple endocrine neoplasia type I syndrome.

\section{METHODS}

The prognostic significance of the following variables was analysed: liver metastases (LM), progression of LM, lymph node metastases, extranodular/extrahepatic metastases, size of the primary tumour, clinical syndrome of hormonal hypersecretion, local invasion by the

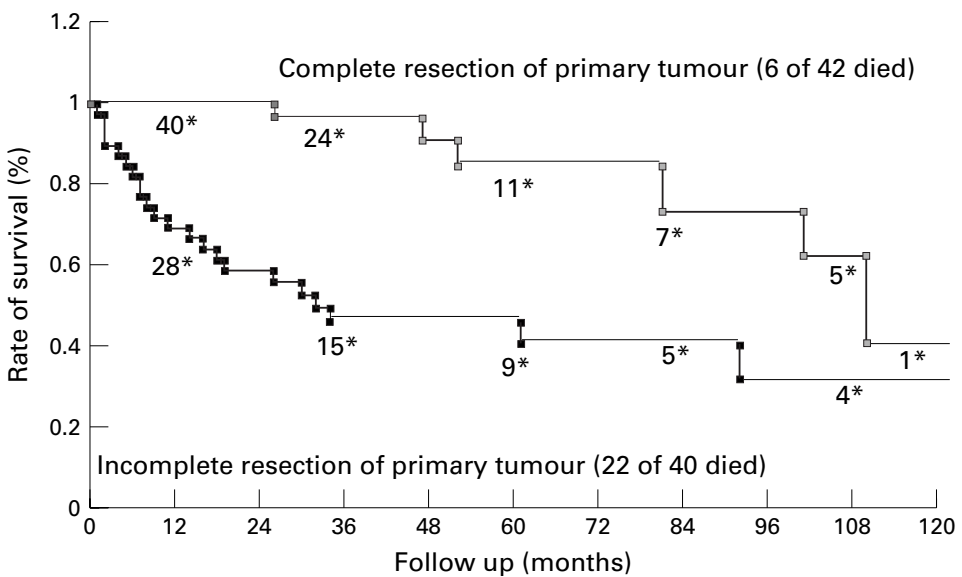

Figure 2 Overall survival after diagnosis among 82 patients with endocrine tumours of the duodenopancreatic area, according to complete resection of the primary tumour (log rank test; $p=0.0001)$. The asterisks indicate the number of patients at risk. primary tumour, complete resection of the primary tumour, and degree of tumoral cell differentiation.

The prognostic significance of the results of medical treatment was not considered, since procedures, drugs, and routes of administration varied and it was not possible to define a homogeneous subgroup of patients.

Localisation of the primary tumour and of distant metastases was achieved in all patients by abdominal ultrasonography and/or computed tomography (CT) scan, and chest $x$ ray. Endoscopic ultrasonography of the duodenopancreas was performed in 56 patients, and somatostatin receptor scintigraphy was performed in 47. Other radiological techniques (cerebral CT scan, bone scintigraphy) were performed according to clinical signs.

The size of the primary tumour at diagnosis, expressed as the largest measurable diameter of the tumour, was assessed by laparotomy ( $\mathrm{n}=$ 57) or radiological techniques (ultrasonography and/or CT scan and/or endoscopic ultrasonography; $n=26$ ). The survival rate of patients with a primary tumour of less than 3 $\mathrm{cm}$ was compared with those with a primary tumour of $3 \mathrm{~cm}$ or above in diameter. ${ }^{11}{ }^{12}$

The size of LM was calculated at diagnosis as the sum of the products of the two largest perpendicular diameters of measurable lesions. Tumoral progression of LM was defined before treatment by an increase in the size of LM by at least $25 \%$ or the appearance of new liver lesions when comparing CT scans performed at an interval of at least three months. Thus, when surgery or chemotherapy was performed within three months of diagnosis of LM, tumoral progression of LM could not be evaluated.

Local invasion of neighbouring organs was identified at laparotomy with histological confirmation $(n=16)$, or was identified by CT $\operatorname{scan}(\mathrm{n}=10)$.

Fifty seven patients had abdominal exploratory surgery. Complete resection of the primary tumour $(n=42)$ was defined surgically as a macroscopically complete resection and histologically by tumour-free resection margins. Complete resection was performed in 13 patients without metastases, in 10 patients with only lymph node metastases (all resected), and in 19 patients with LM in whom 12 were synchronous (two non-resected, five completely resected, and five partially resected) and seven were metachronous (one had partial resection of $\mathrm{LM}$ ).

HISTOLOGY

The degree of tumoral differentiation was reviewed by a single pathologist, in tissue obtained by either surgical resection $(n=52)$ or fine-needle biopsy $(n=21)$ guided by ultrasonography or CT scan. The tumours were classified into three groups based on the classification for pulmonary endocrine tumours. ${ }^{13}$ The first group included insular or acinar patterns. Nuclei were small and no necrosis was seen. The second group was characterised by a lesser degree of architectural organisation with cellular crowding and pleio- 


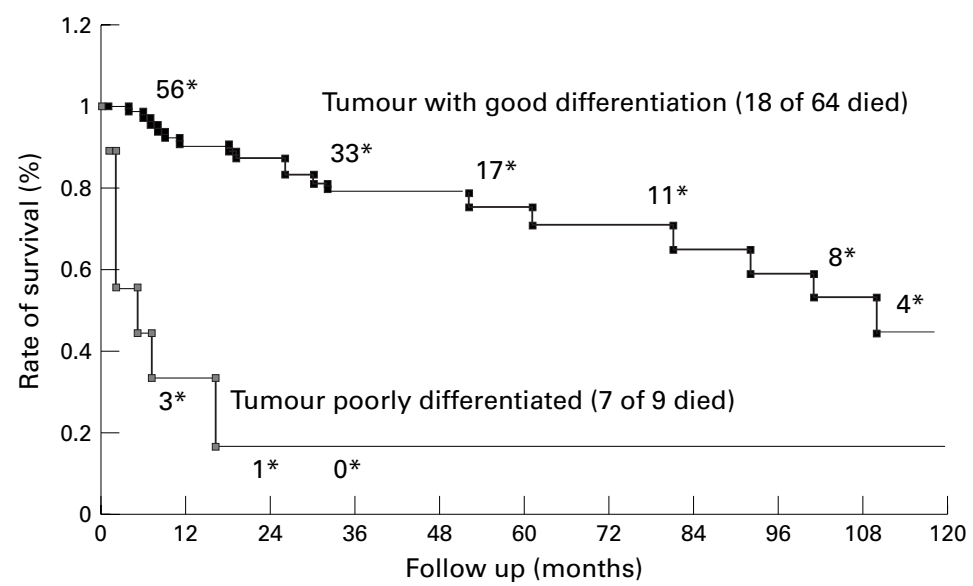

Figure 3 Overall survival after diagnosis among 73 patients with endocrine tumours of the duodenopancreatic area according to the cell differentiation of the primary tumour (log rank test; $p=0.0001)$. The asterisks indicate the number of patients at risk.

morphism. The third group included small and large cell carcinomas. Patients with well differentiated tumours (first two groups) were compared with those with poorly differentiated tumours. In three cases, the tissue samples were insufficient to draw firm conclusions, and six tumours could not be histologically confirmed (gastrinomas).

STATISTICAL ANALYSIS

The primary outcome index was overall survival from the date of diagnosis to the last date of follow up or death. Univariate analysis was performed to compare the death rates in the different subgroups of patients by the $\chi^{2}$ test or Fisher's exact test. Actuarial survival probabilities were calculated by the KaplanMeier method, and compared by the log rank test. Multivariate analysis was performed with the Cox proportional hazards model. The variable "liver metastases" was forced in the model because there were no deaths in the group without LM. p $<0.05$ was considered to be statistically significant.

\section{Results}

Twenty eight patients (34\%) died $17(1-110)$ months (median (range)) after diagnosis. In 27 cases, deaths were related to the tumoral progression of LM. One patient died from postoperative septicaemia after surgery for a gastrinoma with multiple LM.

Table 4 Multivariate analysis of maximum-likehood estimates of selected clinical variables in 82 patients with endocrine tumours of the duodenopancreatic area according to the presence of liver metastases

\begin{tabular}{lll}
\hline Variable & $\begin{array}{l}\text { Conditional risk ratio for } \\
\text { mortality }(95 \% \text { CI)* }\end{array}$ & p Value \\
\hline $\begin{array}{l}\text { Degree of differentiation of tumour } \\
\text { (Poor vs good) }\end{array}$ & $8.11(3.05$ to 21.60$)$ & 0.0001 \\
$\begin{array}{l}\text { Complete resection of primary tumour } \\
(\text { Yes vs no) }\end{array}$ & $4.85(1.94$ to 12.05$)$ & 0.0007 \\
$\begin{array}{l}\text { Extranodular/extrahepatic metastases } \\
(\text { Yes vs no) }\end{array}$ & $2.14(0.98$ to 4.66$)$ & 0.0555 \\
$\begin{array}{l}\text { Lymph node metastases } \\
(\text { Yes vs no) }\end{array}$ & $2.67(0.80$ to 8.89$)$ & 0.1093 \\
$\begin{array}{l}\text { Primary tumour size } \\
<3 \text { cm vs } \geqslant 3 \mathrm{~cm})\end{array}$ & $1.38(0.47$ to 4.05$)$ & 0.562 \\
$\begin{array}{l}\text { Functioning tumour } \\
(\text { Yes vs no) }\end{array}$ & $1.19(0.53$ to 2.70$)$ & 0.672 \\
\hline
\end{tabular}

^ CI denotes confidence interval.
UNIVARIATE ANALYSIS

The following variables were associated with a significant decrease in overall survival: lack of complete resection of the primary tumour $(\mathrm{p}=$ $0.0002)$; LM ( $\mathrm{p}=0.0001)$; lymph node metastases $(p=0.0002)$; extranodular/extrahepatic metastases $(\mathrm{p}=0.0001)$; local invasion of the primary tumour $(\mathrm{p}=0.0001)$; primary tumour size $\geqslant 3 \mathrm{~cm}(\mathrm{p}=0.0011)$; non-functioning tumours $(\mathrm{p}=0.009)$; tumoral progression of $\mathrm{LM}(\mathrm{p}=0.0001)$; poor tumoral differentiation $(\mathrm{p}=0.0001)$.

Table 2 shows the comparison of death rates, the risk ratio (RR) of death, and the five year survival rates for each variable.

The median survival time of patients with or without surgical resection of the primary tumour was 110 and 34 months respectively ( $R R$ of death $4.85 ; 95 \%$ CI 1.96 to $12.05 ; \mathrm{p}=$ $0.0002)$. In patients with poorly or well differentiated tumours, median survival time was 5 and 110 months respectively (RR $11.75 ; 95 \%$ CI 4.38 to $31.53 ; \mathrm{p}=0.0001)$. In patients with or without extranodular/extrahepatic metastases, survival time was 11 and 110 months respectively ( $R R 4.4 ; 95 \%$ CI 2 to $9.5 ; \mathrm{p}=$ $0.0001)$. For the other variables, the death rate in one group was not high enough to calculate a median difference in survival.

To assess factors associated with LM, we compared the frequency of patients with LM in several groups. We found a significant increase in LM among patients with a primary tumour $\geqslant 3 \mathrm{~cm}(\mathrm{p}=0.001)$, with non-functioning tumours $(p=0.043)$, with lymph node metastases ( $\mathrm{p}=0.001)$, with extranodular/ extrahepatic metastases $(p=0.003)$, and with locoregional tumoral involvement $(\mathrm{p}=0.001)$ (table 3).

Comparisons of actuarial survival curves in patients with and without LM, with completely and incompletely resected primary tumours, and with good and poor tumour cell differentiation are shown in figs 1,2 , and 3 respectively.

MULTIVARIATE ANALYSIS

The presence of LM was the most significant prognostic factor. The relative risk of death associated with LM was 8.3 (95\% CI 3.6 to $19.4 ; \mathrm{p}<0.00001)$. When the presence of LM is taken into account, tumour cell differentiation (conditional RR of death associated with poor differentiation $8.11 ; 95 \%$ CI 3.05 to $21.60 ; \mathrm{p}=$ $0.0001)$ and resection of the primary tumour (RR of death associated with no complete resection 4.85 ; $95 \%$ CI 1.94 to 12.05 ; $\mathrm{p}=$ 0.0007 ) remain significant independent indicators of prognosis (table 4).

\section{Discussion}

During the study period (October 1991 to June 1997) in this series of 82 patients with ETDP, 28 patients died after a median follow up of 17 months (range 1-110). In 27 cases, death occurred as a result of tumoral progression in patients with LM. The rate of malignancy (defined by the presence of metastatic spread to lymph nodes, liver or elsewhere) was $77 \%$. These figures support those in the literature and vary depending on hormonal secretion: 5 to 
$10 \%$ for insulinomas, ${ }^{14} \quad 70$ to $75 \%$ for glucagonomas, ${ }^{15} 23$ to $90 \%$ for gastrinomas, ${ }^{16}{ }^{17}$ and 60 to $92 \%$ for non-functioning tumours. ${ }^{2} 18$

In our series, the presence of LM was the most significant survival factor identified by uni- and multi-variate analysis, with a $R R$ of death of 8.3 (95\% CI 3.5 to $19.4 ; p=0.0001)$. The five year survival rates in patients with and without LM were 40 and $100 \%$ respectively, and the median survival was 47 months. These figures are close to those reported in the literature. Studies performed in patients with Zollinger-Ellison syndrome reported a five year survival rate of $20-50 \%$ in patients with $\mathrm{LM}$ compared with $65-100 \%$ in those without. ${ }^{1617} 19$ In one series of 35 patients with digestive endocrine tumours (20 gastrinomas, 12 carcinoid tumours, and three other digestive endocrine tumours) and LM, the five year survival rate was $70 \% .^{20}$

The progressive $(>25 \%$ increase on two consecutive CT scans) or non-progressive pattern of LM was very significantly associated with survival, and helped to identify two subgroups of patients with an actuarial five year survival rate of 34 and $100 \%$ respectively. Mignon et $a l^{20}$ reached similar conclusions in 35 patients with LM of digestive endocrine tumours. These results favour the current therapeutic approach of reserving chemotherapy for LM for those patients with progressive or symptomatic LM. It also justifies radiological follow up of patients with LM, particularly as predictive factors of evolution have not been established.

The degree of tumoral differentiation was an independent prognostic factor from the presence of LM. Poorly differentiated tumours form a subgroup of anaplastic neuroendocrine carcinomas with marked cellular atypia, ${ }^{21}$ which are characterised by rapid tumoral progression and were associated with a median survival of five months in the present study.

Complete resection of the primary tumour was the only other prognostic factor independent of the presence of LM. The RR of death in the absence of resection of the primary tumour was 4.85 (95\% CI 1.94 to 12.05$)$. In the literature, the role of extensive surgical resection is controversial. McEntee et $a l^{2}$ showed that resection of the primary tumour and hepatic cytoreduction was possible with acceptable mortality and morbidity in 37 patients with endocrine pancreatic or carcinoid tumours and LM. The only benefit identified occurred in limited and completely resectable metastatic lesions leading to complete or incomplete remission of symptoms in 85 and $15 \%$ of the patients respectively, with a median duration of 26 months. No benefit in survival was shown. In contrast, incomplete resections were associated with a relapse within 12 months in all cases. Carty et $a l^{23}$ compared 17 patients with pancreatic endocrine tumours who had received extensive resection of all tumoral lesions with 25 inoperable patients: the five year survival rates were 79 and $28 \%$ respectively. This study also noted that the survival rate in operated patients did not improve when metastastic lesions were very advanced. In another study, ${ }^{20}$ there was no improvement in survival in 35 patients with LM of digestive endocrine tumours after resection of the primary tumour. Combined resection of the primary tumour and LM seems to be beneficial in a selected population without extensive secondary lesions.

Interestingly, the presence of extrahepatic metastases was no longer a prognostic factor of survival once correction for the presence of LM had been made. These results confirm those of Stabile $e t a l^{16}$ and Weber et $a l^{11}$ who showed that the survival of 65 and 185 patients with gastrinomas respectively was not influenced by the presence of nodal metastases.

When the size of the primary tumour at diagnosis was $3 \mathrm{~cm}$ or more, the five year survival rate was $47 \%$ compared with $88 \%$ below this threshold $(p=0.003)$. This parameter did not remain significant on multivariate analysis, probably because LM were associated with larger primary tumours: $77 \%$ of patients with a primary tumour $\geqslant 3 \mathrm{~cm}$ had LM compared with $35 \%$ of those with a primary tumour $<3 \mathrm{~cm}$. Weber $e t a l^{11}$ previously showed in 185 patients with gastrinomas that the rate of LM was significantly greater when the primary tumour was $\geqslant 3 \mathrm{~cm}$. Klöppel et $a l^{12}$ considered that a size greater than $3 \mathrm{~cm}$ (and/or the presence of vascular invasion at histological examination) was predictive of aggressive development in non-functioning endocrine tumours. This threshold was lowered to $2 \mathrm{~cm}$ for functioning digestive endocrine tumours.

The traditionally poor prognosis of nonfunctioning tumours is usually attributed to late diagnosis, and LM were already present at diagnosis in $71 \%$ of our patients, compared with $47 \%$ in functioning tumours. In the literature, the rate of LM among patients with nonfunctioning tumours is estimated to be between 60 and $92 \%$ of cases. ${ }^{218}$ Eriksson et $a l^{18}$ reported a five year survival rate of $42 \%$ in patients with non-functioning tumours compared with $80 \%$ in those with functioning tumours. It has been suggested that more nonfunctioning tumours are anaplastic. ${ }^{21}$

\section{CONCLUSION}

In this large single centre series of 82 patients with ETDP, the presence of LM was the factor that most strongly correlated with survival, with an RR of death of 8.3. However, the progression of LM is an important prognostic factor which should be taken into account when planning treatment in these patients. The degree of cellular differentiation had independent prognostic value, and identified a small subgroup of anaplastic tumours with an extremely poor prognosis (median survival five months). The only other independent factor predictive of survival was complete resection of the primary tumour. These results support the strategy of combined surgical resection of the primary tumour and LM whenever possible.

\footnotetext{
1 Friesen SR. Tumors of the endocrine pancreas. $N$ Engl $\mathcal{F}$ Med 1982;306:580-90.

2 Kent RB, van Heerden JA, Weiland LH. Non functioning islet cell tumors. Ann Surg 1980;22:185-9.
} 
3 Thompson GB, van Heerden JA, Martin JK, et al. Carcinoid tumors of the gastrointestinal tract: presentation, managetumors of the gastrointestinal tract: presentation,

4 Kenny BD, Sloan JM, Hamilton PW, et al. The role of morphometry in predicting prognosis in pancreatic endocrine tumors. Cancer 1989;64:460-5.

5 Bordi C, Viale G. Analysis of cell proliferation and tumor antigens of prognostic significance in pancreatic endocrine tumors. In: Mignon M, Jensen RT, eds. Endocrine tumors of the pancreas. Recent advances in research and management. Basel: Karger, 1995:45-99.

6 Metz DC, Kuchnio M, Fraker DL, et al. Flow cytometry and Zollinger-Ellison syndrome: relationship to clinical course. Gastroenterology 1993;105:799-813.

7 Pelosi P, Bresaola E, Bogina G, et al. Endocrine tumors of the pancreas: Ki-67 immunoreactivity on paraffin sections is an independent predictor for malignancy. Hum Pathol 1996;27:1124-34.

8 Viale G, Doglioni C, Gambacorta M, et al. Progesterone receptor immunoreactivity in pancreatic endocrine tumors. An immunocytochemical study of 156 neuroendocrine An immunocytochemical study of 156 neuroendocrine tumors of the pancreas, gastrointestinal

9 Rüschoff J, Willemer S, Arnold R, et al. Nucleolar organizer regions and glycoprotein-hormone alpha-chain reaction as markers of malignancy in endocrine tumors of the pancreas. Histopathology 1993;22:51-7.

10 Mignon M, Bonfils S. Diagnosis and treatment of ZollingerEllison syndrome. Baillière's Clin Gastroenterol 1988:2:67798.

11 Weber HC, Venzon DJ, Lin JT, et al. Determinants of metastatic rate and survival in patients with Zollinger-Ellison syndrome: a prospective long-term study. Gastroenterology 1995;108:1637-49.

12 Klöppel G, Schröder S, Heitz PU. Histopathology and immunopathology of the pancreatic endocrine tumors. In
Mignon M, Jensen RT, eds. Endocrine tumors of the pancreas. Recent advances in research and management. Basel: Karger, 1995:99-120.

13 Travis WD, Linnola RT, Isokos MG, et al. Neuroendocrine tumors of the lung with proposed criteria of large cell neuroendocrine carcinoma. Am f Surg Pathol 1991;15:529-53.

14 Danforth DN, Gorden P, Brennan MF. Metastatic insulinsecreting carcinoma of the pancreas: clinical course and the role of surgery. Surgery 1984;6:1027-34.

15 Prinz RA, Badrinath K, Banerji M, et al. Operative and chemotherapeutic management of malignant glucagonproducing tumors. Surgery 1981;90:713-9.

16 Stabile BE, Passaro E. Benign and malignant gastrinoma. Am $\mathcal{F}$ Surg 1984;149:144-9.

17 Zollinger RM. Gastrinoma: factors influencing prognosis. Surgery 1984;97:49-54.

18 Eriksson B, Öberg K, Skogseid B. Neuroendocrine pancreatic tumors. Clinical findings in a prospective study of 84 patients. Acta Oncol 1989;3:373-7.

19 Mignon M, Ruszniewski P, Haffar S, et al. Current approach to the management of tumoral process in patients with gastrinomas. World 7 Surg 1985;10:703-10.

20 Mignon M, Ruszniewski P, Hochlaf S, et al. Quand proposer une transplantation hépatique aux patients avec métastases hépatiques de tumeurs endocrines? [Résumé]. Gastroenterol hépatiques de tumeurs

21 Moertel CG, Kvols LK, O'Connell MJ, et al. Treatment of neuroendocrine carcinomas with combined etoposide and cisplatin. Cancer 1991;68:227-32

22 McEntee GP, Nagorney DM, Kvols LK, et al. Cytoreductive hepatic surgery for neuroendocrine tumors. Surgery 1990;108:1091-6.

23 Carty SE, Jensen RT, Norton JA. Prospective study of aggressive resection of metastatic pancreatic endocrine tumors. Surgery 1992;112:1024-32. 